\title{
Article \\ Accelerated Testing and Reliability of FDM-Based Structural Electronics
}

\author{
Bartłomiej Wałpuski *(D) and Marcin Słoma (D)
}

\section{check for}

updates

Citation: Wałpuski, B.; Słoma, M. Accelerated Testing and Reliability of FDM-Based Structural Electronics. Appl. Sci. 2022, 12, 1110. https:// doi.org/10.3390/app12031110

Academic Editor: Roland Brunner

Received: 10 December 2021

Accepted: 17 January 2022

Published: 21 January 2022

Publisher's Note: MDPI stays neutral with regard to jurisdictional claims in published maps and institutional affiliations.

Copyright: (c) 2022 by the authors. Licensee MDPI, Basel, Switzerland. This article is an open access article distributed under the terms and conditions of the Creative Commons Attribution (CC BY) license (https:/ / creativecommons.org/licenses/by/ $4.0 /)$.
Micro- and Nano-Technology Division, Institute of Metrology and Biomedical Engineering, Faculty of Mechatronics, Warsaw University of Technology, 8 Boboli St., 02-525 Warsaw, Poland; marcin.sloma@pw.edu.pl

* Correspondence: bartlomiej.walpuski.dokt@pw.edu.pl

\begin{abstract}
With the development of the miniaturization of electronic systems, heat dissipation from components has become an increasing challenge. Structural electronics represent a new approach to this problem. Instead of downsizing all the elements, in this idea, electronic parts of the device are embedded into its mechanical construction. This approach has many advantages, but the reliability of systems constructed this way has not been extensively studied so far. In this work, circuits consisting of silver ink conductive traces were printed on FDM polymer substrates, with or without $0 \Omega$ resistors, and were subjected to accelerated aging testing. The samples were divided into three groups, and for each of them, the mean time to failure was calculated, which for the best group was $8000 \mathrm{~h}$. This paper also presents the mechanism that led to the failure of these systems, as well as actions that will lead to the elimination of this phenomenon.
\end{abstract}

Keywords: structural electronics; reliability; additive manufacturing; 3D printing

\section{Introduction}

Electronics development is currently focused not only on increasing efficiency and performance but on inventing new forms and functionalities. Today, electronics do not have to be bulky, rigid plates but often become flexible [1], soft [2,3], injectable [3], or even invisible to human eyes [4]. Another unconventional form of electronics is structural electronics (SE), in which electronic circuits and components are embedded in device structures such as frames or housing [5]. Thanks to placing components in three dimensions, this approach can reduce device size by increasing design complexity [6], as shown in Figure 1. Miniaturization can reduce manufacturing cost, and this effect can be amplified by adapting SE through a reduction the number of parts and manufacturing steps of a given device. Overall, some structural electronics technologies in specific applications can save up to $70 \%$ of mass and $50 \%$ of cost [7]. Structural electronics can be based on $3 \mathrm{D}$ additive manufacturing, which allows customer-tailored and agile production. As a result, industries such as aerospace, automotive, and production lines are interested in using SE. Structural electronics, thanks to the elimination of tool cost, is a promising technology for electronics prototyping and small scale production. However, for this technology to become widespread, especially in the aforementioned sectors, it is necessary to determine the reliability of devices constructed with it.

Reliability has always been an important aspect of electronics. One of the many advantages of the first transistors was their much longer lifetime than that of tubes [8]. It is still relevant now because electronic systems consist of hundreds or thousands of components and the failure of any one of them can damage the entire device and generate maintenance costs [9]. It has to be remembered that for electronics devices, even $95 \%$ of life cycle costs can be generated after the design phase [10], which shows the importance of reliability-oriented designing and the selection of suitable components. Currently, electronic modules are not only widely available consumer electronics (like smartphones, TVs, computers, etc.), but 
an essential part of most modern devices. For example, in the automotive industry, since the 2000s, electronics have accounted for ca. 25\% of manufacturing costs [11]. Furthermore, electronic sensors are often parts of safety systems, which has led to the zero-defect concept [12]. These requirements have led to a situation in which reliability is not an auxiliary property of a given device but one of the main requirements or even objectives of the design stage of a given electronic system. To accurately estimate the reliability of a given system, besides data on its components (such as mean time between failures), it is crucial to know the mechanisms of failure of the entire device.
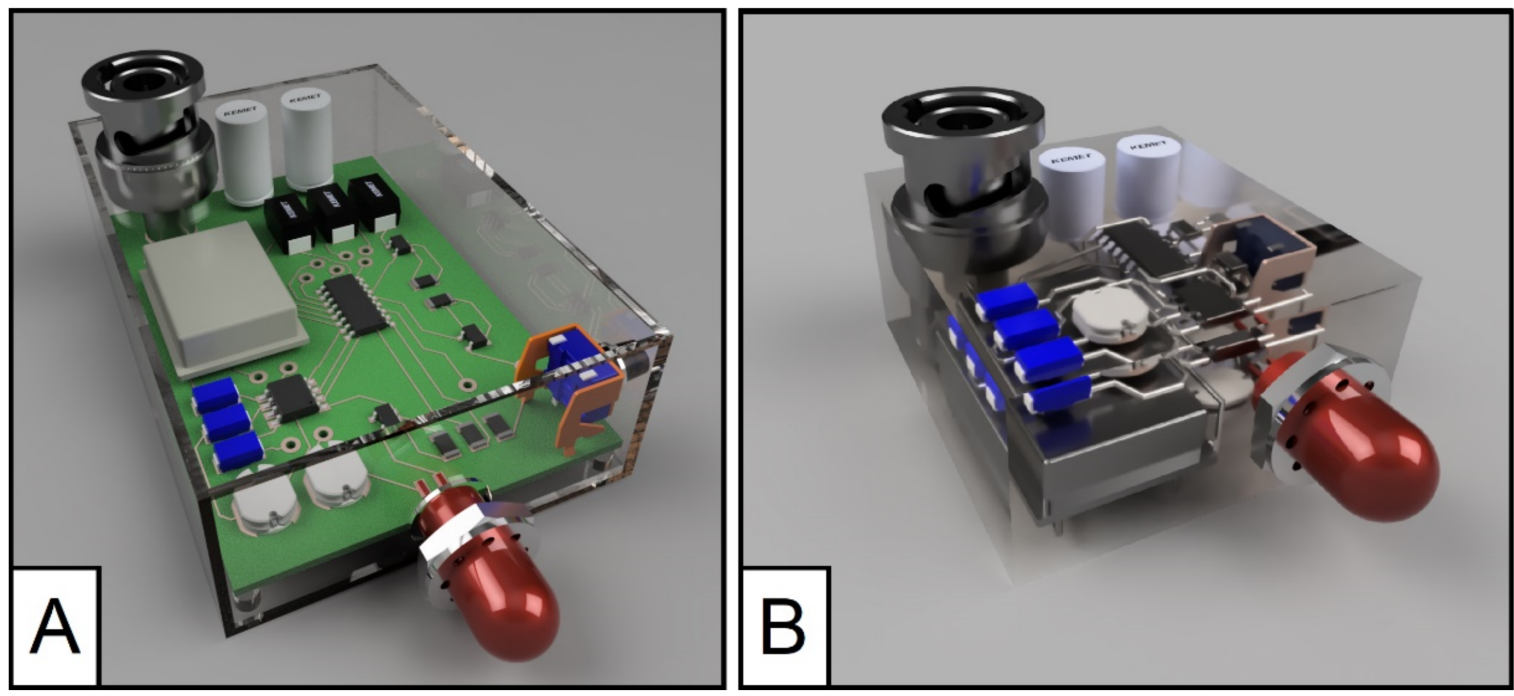

Figure 1. Example electronic device made traditionally (A) and as structured electronics (B).

The estimation of failure mechanisms that occur in structural electronics is a complex issue. These devices combine two functions (mechanical and electronic), so it is necessary to consider both groups. The typical failure, well known from engineering practice, in electrical systems is a capacitor defect. It is true that these components are responsible for $30 \%$ of electronics failures, but the proportion of damages caused by printed circuit boards (PCBs) is similar, and together with solder-based connections, they account for 39\% of failures in electronics [12]. In structural electronics, standard components such as resistors, capacitors, microchips etc. are also used. The most significant difference between PCBs and SE is observed for paths and joints (which may be uniform in SE systems), so this work will focus on them.

One common PCB failure is delamination of the copper foil from polymer substrate. It may be caused by moisture entering the PCB and expanding during the soldering process or operation of electronics at high temperatures. Another reason for this phenomenon may be design error and local exceeding of safe temperature caused by too-high current density in the circuit. This leads to open-circuit situations and can increase the probability of metal migration [13]. Another phenomenon that may cause damage to the electronic system is the short circuit of neighbor traces by tin whiskers or dendrites. This problem is caused by the natural tendency of tin-rich alloys to grow filamentary crystals (whiskers) on the surface of the metal. Whiskers are electrically conductive and mechanically strong and grow faster towards high voltage gradients. Other factors that affect the growth rate of whiskers are humidity and operating temperature, solder composition, contamination, etc. $[14,15]$. The next mechanism that can lead to the failure of an electric device is the formation of voids. These are nonconductive cavities in the solder joints, and their size can reach up to tens of percent of joint size. There are many reasons for their formation, such as evaporation of gases from the solder paste flux, temperature shrinkage, or differences in diffusion coefficients between solder and pads. The formation of voids leads to increased resistance of the joint and an increase in the current density flowing through the solder. This can cause local overheating and further damage to the circuit $[15,16]$. 
On the one hand, many of the mechanisms outlined above are reduced or even eliminated in structured electronics. On the other hand, different phenomena may be enhanced and, furthermore, others not previously observed in conventional systems may occur in new technology approaches (such as additive manufacturing). Because of the layered structure of SE, delamination is a common phenomenon that occurs not only in additively manufactured electronics but in many 3D printed parts [17]. In contrast, the occurrence of whiskers and dendrites in SE should be limited for two reasons. First, in this technique, the conductive material is based on silver, and second, each conductive trace is usually covered with an insulating layer. Because soldering is replaced by bonding with electrically conductive materials, void creation should also be significantly reduced. Nevertheless, additively manufactured objects usually have lower reliability than traditionally manufactured ones [18]. This is caused by the technological thermal stresses or porosity of the fabricated structures. To sum up, the reliability of structural electronics is difficult to predict, so in this work, we investigated how it is comparable with currently available technological solutions. Furthermore, the mechanisms that lead to the destruction of such devices during their operation were investigated.

\section{Materials and Methods}

The experiment for the determination of SE reliability used in this work was accelerated life testing. It was decided to operate the electrical systems at elevated temperatures and calculate the mean time to failure using the formula [19]:

$$
M T T F=\frac{D \cdot H \cdot A_{f}}{r}
$$

where MTTF is mean time to failure, $D$ is number of devices tested, $H$ is test hours per device, $r$ is number of failures, and $A_{f}$ is acceleration factor from the Arrhenius equation, described by:

$$
A_{f}=e^{\frac{E_{a}}{k} \cdot\left(\frac{1}{T_{\text {use }}}-\frac{1}{T_{\text {test }}}\right)}
$$

where $E_{a}=0.7 \mathrm{eV}$ is activation energy $(\mathrm{eV})$ of the failure mode, $k=8.617 \times 10^{-5} \mathrm{eV} / \mathrm{K}$ is Boltzmann's Constant, $T_{\text {use }}$ is operating temperature (in $\mathrm{K}$ ) (usually room temperature), and $T_{\text {test }}$ is test temperature (in $\mathrm{K}$ ).

To simulate structural electrical systems, 2 types of samples were prepared. The first had 6 single traces in 3 different widths, ended with measurement pads at each end. The second type had an additional $0 \Omega$ resistor in the middle of each path. Both types of samples also had a single meandering trace to simulate more complex shapes. The samples were prepared in a multistep process. First, glycol-modified polyethylene terephthalate (PET-G) substrates were printed using a fused deposition modeling (FDM) printer from Graften (Poland). The FDM process involves heating and extruding a thermoplastic material through the printer head and applying it to the required area [20,21]. PET-G filament was purchased from Nebula (Poland) and extruded according to the manufacturer's recommendations, i.e., with a nozzle temperature of $230^{\circ} \mathrm{C}$ and a table temperature of $50{ }^{\circ} \mathrm{C}$. The substrates contained cavities for traces and resistors (if needed). In the next step, FDM printing was stopped, and $0 \Omega, 1218$ SMD resistors from Vishay (Malvern, PA, USA) were placed (this step was skipped in the samples without resistors). Then, cavities were partially filled with PM-460A paste from Henkel (Düsseldorf, Germany) using a custom-built automated dispensing system. Dispensing was performed by extruding paste through the tip using controlled pneumatic pressure [22-24]. In the next step, the paste was dried at $50{ }^{\circ} \mathrm{C}$ for $15 \mathrm{~min}$ by FDM printer hot plate, and then the plate covering the traces and resistors was 3D printed on top of the substrate. The cured ink layer was lower than the surrounding polymer layer, so the first layer of covering plate was printed in midair over traces and resistors, but the small size of cavities (less than $10 \mathrm{~mm}$ ) is not a challenge for FDM techniques. Figure 2 shows the fabrication steps and the appearance of the samples at each step. Finally, 70 samples were produced and divided into three groups. Group A 
consisted of 3 meandered paths and 4 paths without resistors in each tested width $(0.5 \mathrm{~mm}$, $1 \mathrm{~mm}$, or $2 \mathrm{~mm}$ ) and 2 paths with resistors in each width. Group B consisted of 2 meandered paths and 4 paths with resistors in each width. Group $C$ consisted of 5 meandered paths and 6 paths without resistors in each tested width and 4 paths with resistors in each width. In each group, samples were connected in series to equalize the flowing current, and then all samples were placed in a climatic test chamber CTS C-70/200 at $344 \mathrm{~K}\left(71{ }^{\circ} \mathrm{C}\right)$. The temperature at which the accelerated life tests were performed was limited by the glass transition temperature of PET-G, which is approximately $350 \mathrm{~K}\left(77^{\circ} \mathrm{C}\right)$. After connection to the power supply system, the series of samples was connected to an automated data acquisition system to determine the time when failure of any of the samples in the series occurred. It was assumed that after some time, the circuit would break, indicating failure, which was registered as a state in which the measured current value dropped below $20 \mathrm{~mA}$. This test was conducted as a pilot study to check the viability of the technology and not to accurately determine the final reliability of a given sample. For this reason, the number of tested samples was small, and the tests were carried out only up to the failure of the first sample $(r=1)$. The activation energy should theoretically be empirically determined for each process; however, in electronics reliability testing, a value of $0.7 \mathrm{eV}$ is common and provides sufficiently accurate results [25-27]. In these calculations, the operating temperature $T_{\text {use }}$ value was $294 \mathrm{~K}\left(21^{\circ} \mathrm{C}\right)$.

\section{Substrate FDM printing}
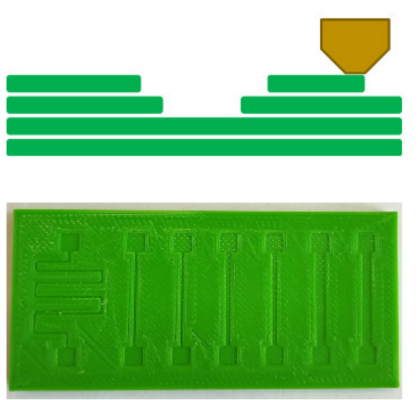

\section{Resistor placing}
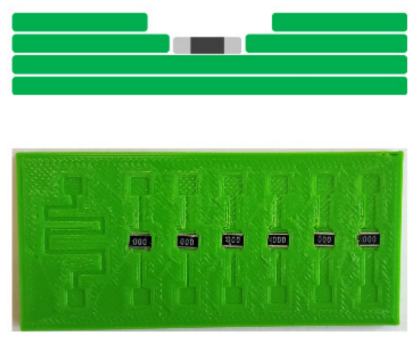

\section{Conductive ink dispensing}
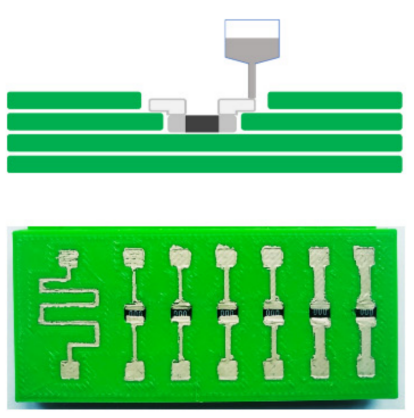

\section{Covering plate FDM printing}
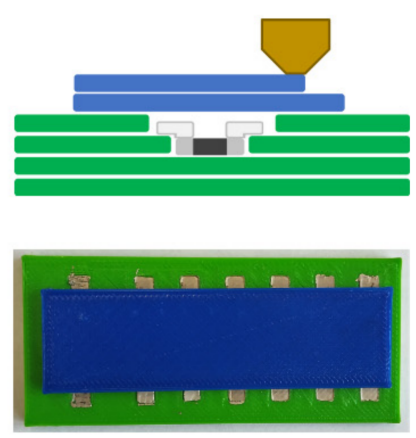

Figure 2. Fabrication steps of tested structural electronics samples and their appearance on each step.

\section{Results}

During the accelerated tests, the flowing current dropped below $20 \mathrm{~mA}$ several times in particular groups of samples. This means that instead of breaking the circuits, a fault with a different operation mechanism occurred. Therefore, the time to the first drop of the current value was used to calculate the MTTF. However, all samples were kept at elevated temperature for about $24 \mathrm{~h}$, and any electrical measurements were made only after this time. Interrupting the test and excluding failed samples could lead to cooling of the chamber and disruption of the test conditions. Table 1 shows the number of samples in each group and the calculated MTTF.

Table 1. Results of accelerated life test of structural electronics circuits. The test was conducted in $344 \mathrm{~K}\left(71^{\circ} \mathrm{C}\right)$, where the assumed use temperature was $294 \mathrm{~K}\left(21^{\circ} \mathrm{C}\right)$.

\begin{tabular}{ccccc}
\hline $\begin{array}{c}\text { Group } \\
\text { Name }\end{array}$ & $\begin{array}{c}\text { Number of Samples } \\
\text { in the Group }(\boldsymbol{D})\end{array}$ & $\begin{array}{c}\text { Number of Samples } \\
\text { with Resistors }\end{array}$ & Test Time $(\boldsymbol{H}), \mathbf{h}$ & MTTF, h \\
\hline A & 21 & 6 & 0.67 & 200 \\
B & 14 & 12 & 2 & 400 \\
C & 35 & 12 & 17 & 8000 \\
\hline
\end{tabular}


The highest MTTF value was observed for the group with the most samples. With the samples connected in series (where the reliability of the whole series is a multiplication of the reliability of individual members), this indicates that the dominant failure process was the so-called "infant mortality" failure [28]. Samples that failed in groups A and B should be detected by the quality check process and eliminated from the production series. A similar conclusion can be drawn from the analysis of the resistance of every sample, as the range of initial value was more than an order of magnitude larger for selected path widths (Figure 3). Even for the best series ( $2 \mathrm{~mm}$ wide traces with resistor), the highest resistance value of the sample was more than three times the value of the sample with the lowest resistance measured. This shows the low repeatability of the fabrication process, which may have affected the spread of the MTTF results. However, despite the described problems, the obtained results are very close to the reliability of systems commonly used in industry: in automotive, the designed target of a lifetime is 10,000 $\mathrm{h}$ [29]. With additional effort and the use of the best currently available technologies, with quality control applied, we should achieve this target.

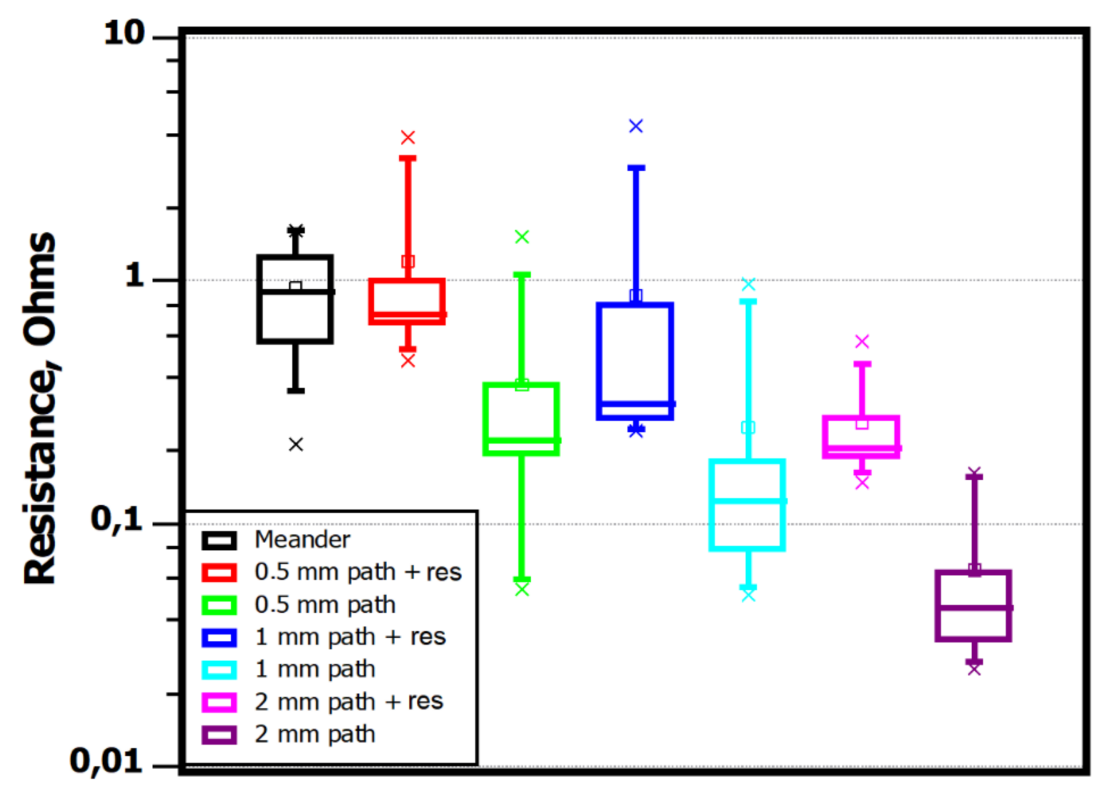

Figure 3. Initial resistance of different groups of 3D printed electronics. The designation "+ res" indicates paths with a $0 \Omega$ resistor.

\section{Discussion}

An unresolved issue remained to explain the mechanism that caused the progressive increase in resistance of the samples. To the authors' knowledge, two types of phenomena leading to the increase in resistance are possible: changes in the geometry of the conduction path or chemical changes in the conductive material. Path dimension change could be caused by electromigration of silver [30-32] or degradation of the polymeric vehicle of the paste, which can lead to loss of integrity. In order to determine the geometry of the samples after the accelerated tests, X-ray computed tomography (CT) of samples with the highest resistance change was performed (Figure 4). The " $X$ " marks visible in Figure 4 are $\mathrm{CT}$ artifacts representing the polymer substrate and do not affect the current flow. The CT observations and measurements indicated only a slight difference in the path dimensions, which may have been caused by the uneven application of the conductive material or due to the measurement accuracy $( \pm 0.05 \mathrm{~mm})$. A $0.1 \mathrm{~mm}$ reduction in dimensions did not explain the two-order of magnitude increase in the resistance value.

After eliminating changes in the geometry of the conductive paths, the next step was to measure and analyze the resistance of each sample. The results of these measurements are presented in Figure 5. It is clear that a significant increase in resistance occurred only 
for samples with embedded resistors. This means that the phenomenon causing this failure occurred at the contact between resistor terminals and printed paths. Void generation was initially excluded because of the low curing and testing temperature of the conductive material, and furthermore, no voids were observed with X-ray tomography. The most likely phenomenon that could cause such an increase in resistance is the formation and growth of an intermetallic layer. The main component of the conductive material was silver micro powder, while the resistor pads were plated with tin base alloy (which was confirmed in energy-dispersive $\mathrm{X}$-ray spectroscopy). These two metals can form alloys with resistivity of up to two orders of magnitude higher than that of pure silver, which was observed while developing Ag-based resistors [33] and microelectronics films [34]. Furthermore, diffusion at the junction of these two metals was observed below the soldering temperature, and the resistivity of such a junction increases in time at an exponential rate [35], which is important for long-term processes.

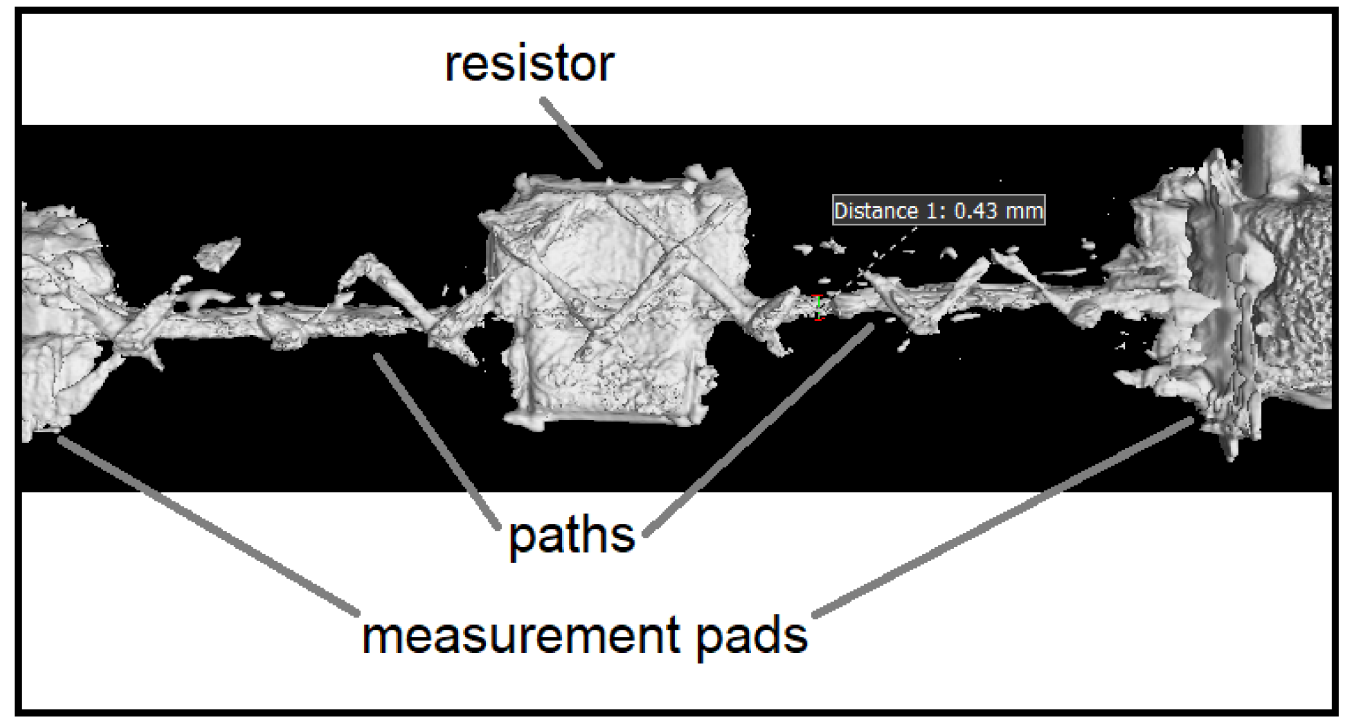

Figure 4. X-ray computed tomography model of sample after accelerated life testing. Initially, the printed trace had about $0.5 \mathrm{~mm}$. The visible $X$ marks are CT artifacts representing the polymer substrate.

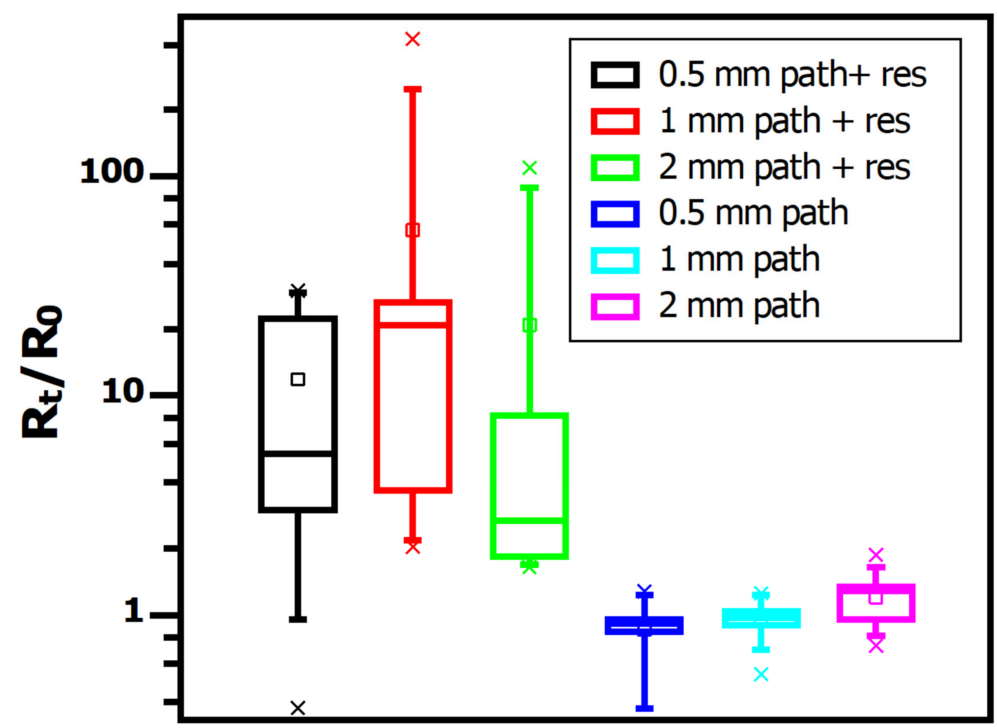

Figure 5. Change of resistance of $3 \mathrm{D}$ printed samples after accelerated aging test. $R_{t}$ represents resistances after test and $R_{0}$ means initial values. The designation "+ res" indicates paths with a $0 \Omega$ resistor. 


\section{Conclusions}

In this paper, the main mechanisms of electronics failure for 3D printed structural circuits were evaluated. We observed that the reliability of structural electronics was not significantly different from that of electronics made by the traditional approach. Current commercially available techniques make it possible to produce devices with MTTF approaching industrial requirements $(8000 \mathrm{~h}$ in this work, against automotive demands of $10,000 \mathrm{~h}$ ). It is expected that the primary phenomenon negatively affecting the reliability of structural electronics is the growth of intermetallic layers. This can be avoided either by developing new electronic components or by developing nonsilver conductive materials, which could be an interesting direction for further research. It should be noted that the reliability of specific devices may vary from this case, but concerns about the robustness of the structural electronics should not be a barrier to their development. Differences in obtained MTTF values shows that the quality of control has a more significant influence on the reliability of products than the technique used.

Author Contributions: Conceptualization, B.W.; methodology, B.W. and M.S.; validation, B.W. and M.S.; formal analysis, B.W. and M.S.; investigation, B.W. and M.S.; resources, B.W.; writing-original draft preparation, B.W.; writing-review and editing, M.S.; visualization, B.W.; supervision, M.S.; project administration, M.S.; funding acquisition, M.S. All authors have read and agreed to the published version of the manuscript.

Funding: This work was financially supported by the Foundation for Polish Science within the FirstTEAM/2016-1/7 project.

Institutional Review Board Statement: Not applicable.

Informed Consent Statement: Not applicable.

Data Availability Statement: The data presented in this study are available on request from the corresponding author.

Acknowledgments: This work was supported by the Metrology and Biomedical Engineering Institute, Warsaw University of Technology, Faculty of Mechatronics.

Conflicts of Interest: The authors declare no conflict of interest.

\section{References}

1. Perelaer, J.; Smith, P.J.; Mager, D.; Soltman, D.; Volkman, S.K.; Subramanian, V.; Korvink, J.G.; Schubert, U.S. Printed electronics: The challenges involved in printing devices, interconnects, and contacts based on inorganic materials. J. Mater. Chem. 2010, 20, 8446. [CrossRef]

2. Kang, J.; Tok, J.B.H.; Bao, Z. Self-healing soft electronics. Nat. Electron. 2019, 2, 144-150. [CrossRef]

3. Rogers, J.A. Electronics for the human body. JAMA J. Am. Med. Assoc. 2015, 313, 561-562. [CrossRef] [PubMed]

4. Lunca Popa, P.; Crêpellière, J.; Nukala, P.; Leturcq, R.; Lenoble, D. Invisible electronics: Metastable Cu-vacancies chain defects for highly conductive p-type transparent oxide. Appl. Mater. Today 2017, 9, 184-191. [CrossRef]

5. Joe Lopes, A.; MacDonald, E.; Wicker, R.B. Integrating stereolithography and direct print technologies for 3D structural electronics fabrication. Rapid Prototyp. J. 2012, 18, 129-143. [CrossRef]

6. Espalin, D.; Muse, D.W.; MacDonald, E.; Wicker, R.B. 3D Printing multifunctionality: Structures with electronics. Int. J. Adv. Manuf. Technol. 2014, 72, 963-978. [CrossRef]

7. Giordano, G. Plastics Get Flexible for Electronics. Plast. Eng. 2016, 72, 14-21. [CrossRef]

8. Fink, D.G. Transistors versus Vacuum Tubes. Proc. IRE 1956, 44, 479-482. [CrossRef]

9. Falck, J.; Felgemacher, C.; Rojko, A.; Liserre, M.; Zacharias, P. Reliability of Power Electronic Systems. IEEE Ind. Electron. Mag. 2018, 12, 24-35. [CrossRef]

10. Arsenault, J.E.; Roberts, J.A. Reliability and Maintainability of Electronic Systems; Pitman Publishing: London, UK, 1980; ISBN 9780273014768

11. Zanoni, E.; Pavan, P. Improving the Reliability and Safety of Automotive Electronics. IEEE Micro 1993, 13, 30-48. [CrossRef]

12. Yang, S.; Xiang, D.; Bryant, A.; Mawby, P.; Ran, L.; Tavner, P. Condition monitoring for device reliability in power electronic converters: A review. IEEE Trans. Power Electron. 2010, 25, 2734-2752. [CrossRef]

13. Baylakoglu, I.; Hedin, E. PCB Delamination. In The ELFNET Book on Failure Mechanisms, Testing Methods, and Quality Issues of Lead-Free Solder Interconnects; Springer: London, UK, 2011; pp. 275-282. 
14. Vicenzo, A. Tin Whiskers. In The ELFNET Book on Failure Mechanisms, Testing Methods, and Quality Issues of Lead-Free Solder Interconnects; Springer: London, UK, 2011; pp. 123-159.

15. Dušek, K.; Bušek, D.; Veselý, P. Overview of Selected Issues Related to Soldering. In Welding—Modern Topics; IntechOpen: London, UK, 2021.

16. Hermans, M.J.M.; Biglari, M.H. Void Formation by Kirkendall Effect in Solder Joints. In The ELFNET Book on Failure Mechanisms, Testing Methods, and Quality Issues of Lead-Free Solder Interconnects; Springer: London, UK, 2011; pp. 105-122.

17. Maqsood, N.; Rimašauskas, M. Delamination observation occurred during the flexural bending in additively manufactured PLA-short carbon fiber filament reinforced with continuous carbon fiber composite. Results Eng. 2021, 11, 100246. [CrossRef]

18. Keleş, Ö.; Blevins, C.W.; Bowman, K.J. Effect of build orientation on the mechanical reliability of 3D printed ABS. Rapid Prototyp. J. 2017, 23, 320-328. [CrossRef]

19. Ellerman, P. Calculating Reliability using FIT \& MTTF: Arrhenius HTOL Model. MicroNote 2012, 1002, 1-6.

20. Kristiawan, R.B.; Imaduddin, F.; Ariawan, D.; Ubaidillah; Arifin, Z. A review on the fused deposition modeling (FDM) 3D printing: Filament processing, materials, and printing parameters. Open Eng. 2021, 11, 639-649. [CrossRef]

21. Ngo, T.D.; Kashani, A.; Imbalzano, G.; Nguyen, K.T.Q.; Hui, D. Additive manufacturing (3D printing): A review of materials, methods, applications and challenges. Compos. Part B Eng. 2018, 143, 172-196. [CrossRef]

22. Jiang, T.; Munguia-Lopez, J.G.; Flores-Torres, S.; Kort-Mascort, J.; Kinsella, J.M. Extrusion bioprinting of soft materials: An emerging technique for biological model fabrication. Appl. Phys. Rev. 2019, 6, 011310. [CrossRef]

23. Jianping, L.; Guiling, D. Technology Development and Basic Theory Study of Fluid Dispensing-A Review. In Proceedings of the Sixth IEEE CPMT Conference on High Density Microsystem Design and Packaging and Component Failure Analysis (HDP '04), Shanghai, China, 3 July 2004; pp. 198-205.

24. Mandrycky, C.; Wang, Z.; Kim, K.; Kim, D.-H. 3D bioprinting for engineering complex tissues. Biotechnol. Adv. 2016, 34, 422-434. [CrossRef] [PubMed]

25. Bayle, F.; Mettas, A. Temperature Acceleration Models in Reliability Predictions: Justification \& Improvements. In Proceedings of the Annual Reliability and Maintainability Symposium, San Jose, CA, USA, 25-28 January 2010.

26. Pecht, M.G.; Shukla, A.A.; Kelkar, N.; Pecht, J. Criteria for the assessment of reliability models. IEEE Trans. Components Packag. Manuf. Technol. Part B 1997, 20, 229-233. [CrossRef]

27. Lakshminarayanan, V.; Sriraam, N. The Effect of Temperature on the Reliability of Electronic Components. In Proceedings of the IEEE CONECCT 2014-2014 IEEE International Conference on Electronics, Computing and Communication Technologies, Bangalore, India, 6-7 January 2014.

28. Holcomb, D.P.; North, J.C. An Infant Mortality and Long-Term Failure Rate Model for Electronic Equipment. ATET Tech. J. 1985, 64, 15-31. [CrossRef]

29. Huai, W.; Liserre, M.; Blaabjerg, F.; De Place Rimmen, P.; Jacobsen, J.B.; Kvisgaard, T.; Landkildehus, J. Transitioning to physics-of-failure as a reliability driver in power electronics. IEEE J. Emerg. Sel. Top. Power Electron. 2014, 2, 97-114. [CrossRef]

30. Magdassi, S.; Grouchko, M.; Kamyshny, A. Copper Nanoparticles for Printed Electronics: Routes Towards Achieving Oxidation Stability. Materials 2010, 3, 4626-4638. [CrossRef] [PubMed]

31. Song, T.B.; Chen, Y.; Chung, C.H.; Yang, Y.; Bob, B.; Duan, H.S.; Li, G.; Tu, K.N.; Huang, Y. Nanoscale joule heating and electromigration enhanced ripening of silver nanowire contacts. ACS Nano 2014, 8, 2804-2811. [CrossRef] [PubMed]

32. Trzaska, Z.; Monchoux, J.P. Electromigration experiments by spark plasma sintering in the silver-zinc system. J. Alloy. Compd. 2015, 635, 142-149. [CrossRef]

33. Horo, J.; Harne, P.G.; Nayak, B.B.; Vitta, S. Low temperature coefficient of resistivity Ag-Cd and Ag-Sn alloys-Structure and transport. Mater. Sci. Eng. B Solid-State Mater. Adv. Technol. 2004, 107, 53-57. [CrossRef]

34. Liu, J.H.; Lin, Y.C.; Lue, J.T.; Wu, C.J. Resistivity measurements of layered metallic films at various microwave frequencies and temperatures using the micro-strip T-junction method. Meas. Sci. Technol. 2002, 13, 1132-1137. [CrossRef]

35. Yamashita, M.; Suganuma, K. Degradation mechanism of Ag-epoxy conductive adhesive/Sn-Pb plating interface by heat exposure. J. Electron. Mater. 2002, 31, 551-556. [CrossRef] 